\title{
Imagining a Sustainable Future: Shaping Emergent Thinking by Reflecting Through Aesthetic Action
}

\author{
Paul W. Chan ${ }^{1 *}$ and Christine Räisänen ${ }^{2}$
}

\begin{abstract}
The contested nature of knowledge about sustainable development makes it difficult to embed sustainable development in engineering curricula, which tend to have a deterministic approach to understanding theoretical concepts. Such an approach does not align well with the emergent thinking of sustainable development, where thinking about the future requires dealing not only with what is known, but also with what is unknown and at times unknowable. Text-based approaches that privilege explicit and codified knowledge are limited in helping students visualise what a sustainable future might look like. To facilitate such visualisation would require expansion of the repertoire of tools and artefacts beyond text-based materials. In this article, we critically reflect on a series of student-centred 'Open-space' workshops over the past several years aimed at promoting debate and co-production of knowledge around developing sustainable futures using a range of artefacts such as pictorial illustrations, wiki terms, art materials and chill-out music. Attention is paid on critically appraising the role artefacts play in developing knowledge to empower students to collectively reflect on, imagine and visualise sustainable futures.
\end{abstract}

\section{Keywords}

artefacts, participant observation, rich pictures, sensemaking.

\footnotetext{
${ }^{1}$ School of Mechanical, Aerospace and Civil Engineering, The University of Manchester, Sackville Street, Manchester M13 9PL, United Kingdom *Corresponding Author: E-mail: paul.chan@manchester.ac.uk

${ }^{2}$ Chalmers University of Technology, SE412 96, Gothenburg, Sweden
} 


\section{Introduction}

Since its inception in the 1980 s, the sustainable development agenda has increasingly gained legitimacy in mainstream political, business and academic discourses (see e.g. Martins et al., 2006), from environmental concerns regarding global warming and climate change, to the sustenance of economic prosperity, and progress made on social justice. Governmental and corporate policymakers across the globe are gradually putting credence and effort into creating a more sustainable future. The higher education sector has responded to this movement by incorporating critical aspects - economic, social and environmental perspectives - of the sustainable development agenda within the various curricula (see e.g. Chau, 2007; Stephens et al., 2008; Sammalisto and Lindhqvist, 2008; Holmberg, 2014, and; Lönngren et al., 2016). Within engineering professions, there is increasing acknowledgement of the agenda in professional thinking, and there are ongoing debates as to how this might be reflected within professional codes of practice (see Allenby et al., 2007).

Whilst the literature has been comprehensive in its treatment of how the design of curricula, in terms of content and process issues (see e.g. Boyle, 2004; Fenner et al., 2005; Azapagic et al., 2005; Chau, 2007, and; Sammalisto and Lindhqvist, 2008), may embrace the sustainable development agenda, the teaching and learning activities and especially the mediating tools and artefacts used in the engineering education context have been given scant attention (for exceptions, see e.g. Quist et al., 2006, and; Segalàs et al., 2009). Yet, a successful strategic re-design of the content and process of curricula cannot be achieved without recognising the various mediating roles tools and artefacts play in enhancing students' understanding of the complexities and interdependencies of multiple concepts associated with sustainable development. In this article, we address this gap by presenting and reflecting on a novel method for teaching and learning how the conceptualisation of sustainable development and engineering courses interlink, paying particular attention to the role of tools and artefacts in integrating sustainable thinking within two Masters-level project management programmes.

One reason for the lack of attention on teaching and learning activities, tools and artefacts may be the persistence of didactic lecturing as the main medium of knowledge transfer in engineering education, which in turn gives little space for experimenting with new teaching and learning methods (see e.g. Bernold, 2007; Jones, 2010, and; Duah et al., 2014). Addressing the complexities of the sustainable development agenda requires students to appreciate sustainable development as a 'wicked problem' (Rittel and Webber, 1973); as a problem that "has no definitive formulation and no conclusively 'best' solutions and, furthermore, that the problem is constantly shifting" (Hjorth and Bagheri, 2006: 78). Therefore, rather than to frame knowledge about sustainable development as settled science, there is a need to develop students into reflective practitioners in action (Schön 1984). This would also be in line with current thinking in engineering education, where "science is no longer understood as a purely logical, machine-like activity but a highly contextualized process that results in ever-changing theories with which humans attempt to understand the world" (Lönngren and Svanström, 2016: 154).

Meeting future challenges of the sustainable development agenda requires a constructivist mindset where, as Jones (2010) argued, the focus is not on "transferrals of information", but "students in dialogue with the teachers, and the educational goal of 'posing of the problems of human beings in their relations with the world"' (p. 400). In a recent review of engineering education, Bubou et al. (2017) criticised the information-transmission mode that prevails in the didactic lecture for failing to prepare engineering students for the global challenges that graduates would face in the future. While Bubou et al. can see the merits of the didactic lecture in transmitting disciplinary knowledge, they also called for more transformational and sustainable approaches to engineering education that would enable engineers to proactively meet changing needs of society. As knowledge about sustainable development is still incomplete (see Chan and Cooper, 2010), there is a need to reduce emphasis on transmission of 
disciplinary knowledge, and to move towards more transformational learning as indicated by Jones (2010) and Bubou et al. (2017).

Learning, therefore, needs to be action-driven and include time for thinking and reflection loops, allowing for both individual reflection and, more importantly, collective reflection. Through collective reflection, both students' and teachers' perspectives and past experiences may be tapped into, and new perspectives can emerge and be articulated. Knowledge becomes a collective endeavour in the classroom rather than an individual, competitive acquisition to be tested and graded - then often forgotten. Schön (1978) advocates two kinds of reflective exercises for learners: reflection-on-action and reflection-inaction. The former entails reviewing the theory of and/or prior action, as well as following up on accomplished action. The latter entails continuous question-raising while undertaking an action, where the crucial question is not "what should be done", but "why should it be done in this way" and "what are the consequences when it is done in this way" and "is there a more effective way?" In other words, reflecting-on and reflecting-in-action nurture double-loop learning (Argyris and Schön, 1974), where students are not only challenged on what needs to be changed, but also to reflect on their own underlying assumptions in moving towards a more sustainable future.

The purpose of this article is to critically reflect on the teaching and learning activities, tools and artefacts used to deliver a novel workshop over the past seven years, intended to encourage such participative action-driven learning about sustainable development. These workshops form part of a leadership course delivered to cohorts of postgraduate engineering project-management students in Sweden and the United Kingdom. The central activity of the workshop is based on students creating a rich picture of their visions of the future. Two types of mediating tools were provided: visual images and wiki-terms to stimulate the students' mental frames, and traditional art and craft tools such as empty A1 paper, coloured pens, glue and scissors. Through this activity, we harness the power of images (Rehal and Birgesson, 2006) in a playful setting
(Meadows et al., 2016) to facilitate dialogue and learning about what constitutes a sustainable future. As mentioned earlier, while there is a lot already written about the strategic design of courses and curricula, far less attention has been paid to the mundane tools used in everyday activities of teaching and learning. We address this gap in this article by examining how these tools have enabled students to rapidly appreciate and reflect collectively over the difficulties of envisioning sustainable future as well as over the process by which they have generated the rich pictures of their visions of the future. Our discussion highlights the limitations of conventional forms of instruction-based teacherled learning objectives, and reflects on the educational outcomes attained by an exercise which fosters reflection on and in action. The contribution of this article is to offer deeper insights into the role mediating tools and artefacts play in helping students appropriate the complexities of the sustainable development agenda by reflecting in and on action.

This article is organised in three sections. A salient review of the literature is first presented summarising progress made in embedding sustainable development within engineering curricula in universities. The review highlights how dynamic and incomplete knowledge is about sustainable development. Consequently, this renders traditional, objectivised views on knowledge transfer somewhat inadequate. Furthermore, in the transformation of engineering curricula, much more focus has been placed on strategic concerns, including processes and policy frameworks in universities, and structural characteristics of interactions between universities, industry and wider society, than on the tactical approaches associated with the practices of teaching and learning. Following the literature review, the rationale of the workshop and the significance of the visual aids and crafting tools are explained. This is followed by discussion of two key observations, which point to the difficulties encountered by engineering students in dealing with the fuzziness of the sustainable development agenda and the benefits of using visual aids and empty spaces to create individual and collective knowledge beyond text. Finally, the article 
concludes with a discussion of the role of the educator in unleashing the potential of using a variety of mediating artefacts to enable the students to grapple with emergent thinking about sustainable development.

\section{Embedding Development in Engineering Education in Universities: Where are we now?}

At its core, the sustainable development agenda, which rose to prominence after the publication of the well-known Brundtland report (World Commision on Environment and Development, 1987), is about ensuring a good quality of life for everyone, now and in the future (see also the UK Government, 1999). de Haan (2006) noted that the attention placed on sustainable development stemmed from a stark recognition of ecological crises confronting modern-day society and the quest to remedy social injustice that prevents equal opportunities for every human being across the world. Resolving these environmental and social problems requires an understanding of economic perspectives as well (see e.g. Pearce et al., 1989). Hence, the sustainable development agenda is colloquially referred to as the triple-bottom-line (see Elkington, 2004, and; UN, 2005), ensuring the sustenance of profits, people and planet.

However, knowledge about sustainable development remains incomplete, with many aspects still being debated on and researched. For instance, the precise scale of the problems associated with sustainable development, and how far interventions should go has led Neumayer (1999) to argue that "natural and economic science of global warming is unable to provide unambiguous answers" (p. 41; see also Ekins, 2003). Wackernagel et al. (2004) noted that it is certainly difficult to establish what good practices need to be adopted by the present generation. Therefore, societies are left to their own devices to establish the extent by which current consumption is checked in order to safeguard a more sustainable future; such ethical judgements are framed within the so-called precautionary principle (Neumayer, 1999).

The incompleteness of knowledge about sustainable development presents a major obstacle to efforts made to incorporate sustainable development within engineering education. Traditionally, engineering degree programmes have adhered to a deterministic and technocratic view of knowledge as a packaged product that can be transferred from the teacher/expert to the student/novice, and solutions to perceived problems are generally only allowed a narrow margin for manoeuvre (see Schön, 1984; Räisänen, 2004, and; Fenner et al., 2005). Therefore, it is unsurprising to note that engineering students often conflate their understanding of the sustainable development agenda with technological solutions to environmental problems (see Segalàs et al., 2009), and that their knowledge about wider societal and economic issues remain somewhat unsatisfactory (Azapagic et al., 2005). Attempts have been made to redress this myopia. These range from cursory treatments such as bolting on aspects of social science to engineering degree programmes (Quist et al., 2006), to radical calls for shifting away from conventional normative science to curricula that enable students to better understand the complexities of sustainable development (Colucci-Gray et al., 2006). The teaching and learning of such a complex agenda runs counter to the contemporary pedagogical practice of framing manageable chunks of discrete learning outcomes (see Hussey and Smith, 2002 for a critique of the problems with learning outcomes in higher education). In a survey of sustainable development teachers, students and practitioners, Mulder (2010) confirmed that the treatment of sustainable development was far from normative, and that there was not a singular, coherent view of a sustainable future. This makes the normal articulation of concrete learning outcomes challenging.

Over the past decade, higher education has been transformed in order to embrace the sustainable development agenda. For instance, Sammalisto and Lindhqvist (2008) urged universities to undertake a root-and-branch review of all aspects of teaching, learning and research to see what was 
being done to integrate concepts of sustainable development within these activities. Moore (2005a) considered the role of universities as change agents, and recommended the creation of sustainable development education beyond the classroom; she encouraged universities to integrate sustainability into all university decisions and to actively encourage transdisciplinarity and collaboration across all university functions of teaching, research and service. Wright (2010) considered the significance of leadership from university presidents in promoting sustainable development practices across all levels of the university hierarchy. Martins and Mata (2006) and Stephens et al. (2008) reflected on the external interactions with universities and suggested that stakeholders from industry and communities be involved to promote wider understanding of sustainable development.

In summary, consensus is building around a number of recurrent themes. The contingent and emergent nature of knowledge about sustainable development has been acknowledged. Instead of focussing on universal truths as is the case in conventional, normative science, the emphasis should be on transformative education, where students are encouraged to undergo a journey of self-discovery, to participate in the formulation of their own learning outcomes, and to construct knowledge using their own experiences of the world juxtaposed with divergent points of view (see Moore, 2005b, and; Mulder, 2010). According to Colucci-Gray et al. (2006), students would benefit by developing the ability to engage in scientific argumentation so as to articulate, and convince others, of their views about the 'truth' and to better handle conflicting positions in tackling the complexities of the sustainable development agenda. Students should also have the space to engage in inter-disciplinary dialogue, and expose themselves to a mixture of interactive methods (see e.g. Bergeå et al., 2006, and; Segalàs et al., 2009).

However, the attention hitherto has been on strategic concerns, where the focus has either been on structural characteristics of higher education to embrace the sustainable development agenda (i.e. the way universities organise internal processes and/or external relations) or the (re-)design of the curriculum. Consequently, there is relatively less attention paid to the scrutiny of the (tactical) practices of teaching and learning of sustainable development. There seems to be a tacit assumption that as long as the strategic concerns are addressed, the practices would be unproblematic. Therefore, this article contributes by offering deeper insights into one such practice of teaching and learning the sustainable development workshop. We present a critical reflection of the tools and artefacts used during the workshop in order to explore the role these play in enabling effective knowledge construction and knowledge exchange.

\section{The Empirical Context and Methods}

\section{The Workshop Setting and Learning Outcomes}

The workshop forms part of an elective course entitled Leadership and Communication within an international Masters-level programme in project management at a Swedish university (approximately 60-80 students per year). This workshop is also part of a mandatory course within a large Masters-level programme in project management on People and Organisations in a British university (approximately 300-350 students per year. The course was originally designed on the Swedish programme such that academic and industry experts are invited to run a day-long workshop on a specific theme each week of the course. Students then work in groups to complete a written reflection that demonstrates their learning of each of the weekly themes. The specific workshop reported here relates to the theme of "Leadership, futures thinking and sustainable development." The workshop was first carried out in February 2009, and subsequently repeated to a similar group of students in the UK university. The critical reflection presented here draws upon the observational notes of the educators involved in the cohorts of students over the past seven years, supplemented by the reflective texts produced by the students. Each cohort comprised around 70 students in the Swedish programme and around 300 students in the British programme. 
The workshop runs over a whole day and is designed to allow students to undergo a transformative learning experience, enabling them to engage in a meaningful dialogue with their peers and teachers on their understandings and visions of a sustainable future (Moore, 2005b; Colucci-Gray et al., 2006, and; Bergeå et al., 2006). The 'learning outcomes' of the workshop session were loosely framed around three key issues: (i) to explain various theoretical approaches to understanding leadership and communication; (ii) to discuss futures thinking and sustainable development within the leadership context, and (iii) to have an enjoyable experience. These three outcomes serve more as a guide to signpost the activities of the workshop for the students, as opposed to a method of commoditising the learning experience (Hussey and Smith, 2002). Conventional didactic lecturing was kept to a minimum for the workshop, except to reiterate key theoretical concepts of leadership which the students would have heard about numerous times, albeit from different perspectives throughout the course, and more importantly, to explain the format of the workshop.

The format of the workshop is designed to maximise opportunities for dialogue and selfdiscovery. To this end, a number of activities were incorporated. Firstly, ice-breaking sessions were strategically planned to build students' confidence in sharing their ideas with the wider group, and included such activities as "Identify the picture of leaders" and "What would you say in your interview for a leadership position?"3 The focal point of the workshop, however, centred around the "Rich pictures" activity. After the theoretical preliminaries and ice-breaking activities, students were tasked to:

\footnotetext{
3 "Identify the picture of leaders" involved getting students to name the pictures of various high-profile people (e.g. politicians, CEOs, celebrities etc.), which would include key figures from each of the national contexts. "What would you say in your interview for a leadership position?" was designed to get students to assume the role of a particular character, fictional (e.g. Harry Potter, Bart Simpson etc.) or real (e.g. politicians, CEOs, celebrities etc.), and they had to come up with a
}

Firstly: physically re-shape the room by moving the tables and chairs to the sides of the room. Thus, a large empty space was created;

Secondly: to organically form small groups (of no more than 8 members) and to individually reflect on their own vision of what a sustainable future could look like and to share their visions in their groups;

Thirdly: to design a group poster to illustrate their collective vision of a sustainable future and to display the posters around the room to facilitate open discussions.

To generate collective visions of the future and articulate this within a poster can be an extremely daunting task for students with an engineering background. The open and abstract nature of the activity may cause anxiety since engineering students are conditioned, rightly or wrongly, to deal with discretely bounded problems. To help students develop their rich pictures, a wide variety of visual images representing e.g. poverty, worklife balance, water shortages, climate change, economic well-being as well as a number of "wikiterms" defining contemporary issues (e.g. nanotechnology, biomimicry, intergenerational equity etc.) were printed on postcard-sized paper and scattered across the empty space of the workshop room (see Fig. 1 "Left" below) 4 .

This organic manner of self-organising follows the "Open-space" format developed by Owen (2008), who based his idea on the effectiveness of coffeebreak conversations outside the formal proceedings of conferences he had attended and organised. The "Open-space" format is a rapid way to encourage "situations where a diverse group of people must deal with complex and potentially conflicting material in innovative and productive ways. It is particularly powerful when nobody knows the

brief paragraph of no longer than 50 words to say why they were worthy to assume a leadership role. The icebreaking sessions were meant to be interactive on the one hand, and to stimulate the students to appreciate emergent thinking with reference to leadership on the other (Chan and Cooper, 2010).

4 For a .pdf copy of the images used in this workshop, please email the corresponding author of this paper. 


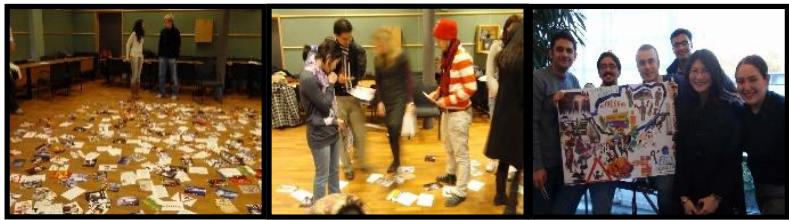

Figure 1. Photographs from the Swedish workshop (Left: at the start of the exercise; Middle: students making sense of the activity, and; Right: a group of students with their 'rich picture').

answer, and the ongoing participation of a number of people is required to deal with the questions" (Owen, 2008: 15). It seemed reasonable that such a workshop format would be beneficial to encourage students to grapple with the complexities and conflicting nature of the sustainable development agenda in a very short time. We wanted the students to actively create a "new" learning space, hence the symbolic reshaping of the work space. To further enhance the experience, we played contemporary chill-out music in the background to simulate the environment of a lounge.

\section{Data sources: Observations and reflective logs}

The purpose of this article is to critically reflect on the workshops and evaluate the teaching and learning activities, along with the mundane tools and artefacts used in running the workshop. To enable this critical reflection, our approach is of an autoethnographic kind. In autoethnography, the aim is not to generate theory, but to situate our own experiences as practitioner researchers within the broader teaching and learning context (Hannon and Bretag, 2010). Autoethnographic accounts of teaching and learning in higher education have become increasingly popular, in part because such accounts produce more authentic stories of what goes on in practice, and it allows educators to selfstudy and reflect on their practices and thus develop self-awareness (see e.g. Moustakim, 2007; Pillay et al., 2016, and; Hains-Wesson and Young, 2017). Reflective practice is central in such selfstudy, since method in the scientific sense cannot be bracketed away as a clearly-defined framework in the writing of autoethnography. As Forrest et al.
(2012) explained, "it is always easier to observe the framework within which someone else's thoughts, feelings, and behaviours are embedded, rather than to see, much less challenge one's own" (p. 710). By reflecting on our own practices without an $a$ priori framework of analysis, we are able to lay open our assumptions that inform our teaching and learning practices. In countering criticisms of how autoethnography reduces research integrity, Hannon and Bretag (2010) argued that "in foregrounding our perspectives and context we make visible what is rarely apparent to the reader, our own agendas" (p. 109). They maintained that as insider researchers, their insights add to the validity of their engagement with the research context, since they do not pretend to be disinterested parties to the reader.

Inspired by Hains-Wesson and Young (2017), four data sources allow for our autoethnographic account to emerge. First, each of us maintained notes on our personal experiences of running the workshop. Second, both of us collaboratively reflect on our notes, supplemented by the regular review processes in our respective institutions (e.g. end-of-unit evaluation questionnaires, feedback from student-staff committee meetings, annual programme reviews). Third, a key feature in autoethnography lies in our reflection of the theoretical literature that helps us make sense of our own practices in running the workshop. Fourth, we also collected reflective logs from students who participated in the workshop. Here, there is a difference between the reflective logs collected in Sweden and in the UK; in the former institution, these $\operatorname{logs}$ form part of weekly submissions that contribute to the assessment, whereas in the latter, the reflective logs are posted on the weekly online discussion blogs and are unassessed.

Our analysis of the data is guided by a number of key questions, including (a) what worked well; (b) what surprising events occurred; (c) what learning outcomes were achieved by both the student and the educator; and, (d) what could be modified to improve the workshop. Since the first workshop, we have interacted with over 2,500 students who have experienced this workshop. Feedback on the workshop has consistently been positive with 
satisfaction scores of between 4.3 and 4.7 ( 5 being the "most satisfied" ${ }^{5}$ ) achieved over the last seven years. See also Table 1 for typical, more recent examples of qualitative feedback received on the workshops. In the next section, we will discuss three critical observations from our reflections.

\section{Critical Observations}

In reviewing our observations, two critical aspects strike us as interesting (and in some cases, surprising). These will be discussed in terms of the students' ability to cope with emergence and the role artefacts play in helping students maximise sensible knowledge beyond text.

\section{Breaking with the tradition of objectivised knowledge transmission: coping with emergence}

Early on, we highlighted the tension between the traditions of engineering education that emphasises the transfer of objectivised knowledge commoditised in discrete, manageable chunks, and the fuzzy and emergent nature of knowledge about the sustainable development agenda. Our first striking observation is the level of discomfort shown on many of the students' facial expressions, and in their body language, at the initial stage of the "Rich pictures" activity. Students have remarked that they are used to dealing with textual and numerical information, and struggle to draw a picture of, or freely describe, "fuzzy knowledge" (Schön, 1984). The open-ended nature of the activity faced some resistance at the outset because students did not know "what the teacher wanted." It was as if students were programmed to be subservient to the powers of the teaching faculty since they perceived that the educators held the key that unlocked the deep chambers of knowledge (see Jones, 2010, and; Duah et al., 2014). It was crucial that we empathised with the students' abilities to cope with this emergent process by reassuring them that "there really isn't a right answer" and that all

\footnotetext{
${ }^{5}$ At the end of each course unit, students are asked to rate the statement 'This course is excellent' with a Likert Scale of 1 to 5 ( 1 being 'strongly disagree' and 5 being 'strongly agree'). This applies to both the British and
}

forms of posters would be held with equal regard whether these were artistically-inclined or textually-framed.

We also observed that the act of getting students to move the physical objects of tables and chairs, and the scattering of the visual aids and tools that enabled the production of the "Rich pictures", not only generated a certain level of intrigue among the students, but also bestowed ownership of the activities and events to them. We noticed that with this symbolic ownership followed a sense of responsibility in the outcomes. The fact that students had to walk about and select among the scattered images, reach out for the marker pens, glue and flipchart paper on the floor, and choose where and how they would work meant that students 'walked-the-talk'; we saw how they were making sense of what was going on as they moved around the room, around the spread-out artefacts, and around each other. While the "Open-space" was intended to encourage interaction, dialogue and collective reflection, it was clearly evident and heartening to note that this actually occurred very rapidly at the start (see Fig. 1 "Middle" above). It was found, on every occasion that the workshop was run that students moved very quickly from a zone of discomfort with the fuzzy nature of the task to a zone of discovery and dialogue where students focused their attention on discussing the nature of the visual images and what these meant to them individually and collectively. These observations contradict studies showing that engineering students are not particularly keen on pedagogical practices outside the didactic lecture, especially if these entailed an intense level of interaction (Bernold, 2007).

Swedish institutions. Our university administrators take this score to indicate how satisfied students are with the respective course units. 


\begin{tabular}{|c|c|}
\hline Cohort & ypical feedback \\
\hline Sweden & $\begin{array}{l}\text { "Regarding the development of our leadership skills, the most important thing is to have a vision of the future. This has to be a clear picture so that the way } \\
\text { towards reaching it could be tangible for the person. One also needs training and exercises." (Group-assignment reflection, 2012-2013 cohort) } \\
\text { "We produced, in small groups, visions of the future using a collection of powerful images for inspiration. Some of the premonitions produced were haunting, } \\
\text { others more optimistic. Personally, our own group produced two split paths portraying different glimpses into the future; one led down the road of despair, } \\
\text { poverty and environmental decline; but the other was full of potential, adventure and happiness. Needless to say, it was a very thought provoking exercise. It } \\
\text { revealed people were afraid of the unknown, and that it was easy to focus on the negative possibilities and adopt a pessimistic outlook. However, a good } \\
\text { strategy soon evolved which went along the lines of 'plan for the worst, hope for the best'. This could not be more applicable than for the current economic } \\
\text { climate" (Group-assignment reflection, 2013-2014 cohort) } \\
\text { "[The] course has been an explorative journey into the heart of the concept of leadership, and has helped us to comprehend one of the most important yet little } \\
\text { understood subjects in everyday life." (Group-assignment reflection, 2014-2015 cohort) }\end{array}$ \\
\hline $\begin{array}{l}\text { United } \\
\text { Kingdom }\end{array}$ & $\begin{array}{l}\text { "The workshop is designed perfectly. Really, really benefit from them. We all had fun." (Unit evaluation questionnaire, 2014-2015 cohort) } \\
\text { "Workshop was memorable and informative. I don't usually like them, but some important project management tools to learn." (Unit evaluation questionnaire, } \\
2015-2016 \text { cohort) } \\
\text { "Those activities or quizzes might seem childish in the first place but they were actually meaningful as they helped us to relate back to our daily experience." } \\
\text { (Unit evaluation questionnaire, 2016-2017 cohort) } \\
\text { "We feel like we were in the kindergarten again. No chairs, no tables, which may make us feel uncomfortable at first, since they are so important in our daily } \\
\text { study. A research says, redesigned learning spaces can engage students and faculty members, which increases in students' ability to achieve higher grades } \\
\text { and in students' motivation to attend class. I felt your seminar is a reflection of this, and they are thought provoking" (5 December 2015, Reflective Log) } \\
\text { "It required us to be artistic, something I am not very good at. However, we worked as a team and everyone automatically was working on what they did best, } \\
\text { with no one allocating the roles. Two people in the group had impressive drawing skills and that's what they did! I helped in brainstorming and gathering } \\
\text { "resources' to use for the overall project. In the end we ended up with an informative and creative poster, something I definitely would have struggled to do } \\
\text { alone." ( } 7 \text { December } 2015 \text {, Reflective Log) }\end{array}$ \\
\hline
\end{tabular}

Table 1. Example feedback from recent cohorts of students. 


\begin{tabular}{|l|l|}
\hline Cohort & Typical feedback \\
\hline $\begin{array}{l}\text { United } \\
\text { Kingdom }\end{array}$ & $\begin{array}{l}\text { "I was quite amazed of different vision that people have and understood how challenging setting a vision is. This demonstrates how we should still work } \\
\text { hard to develop our leadership skills for it is so important in project delivery [...] we should be able to communicate and understand the intended message." } \\
(13 \text { December 2015, Reflective Log) } \\
\text { "It is quite difficult to achieve a goal by different people together. Since everyone has its own opinion on the things we see and the things we do. In this kind } \\
\text { of situation, coordination is important. (14 December 2015, Reflective Log) } \\
\text { "I think as a team member it is also important to show my own opinion, so if I don't agree with the team leader, I think my idea is better, but the time is } \\
\text { limited. Then how should I communicate with team leader? [...] As a team member, should I make my voice heard or just do whatever the boss said?" (8 } \\
\text { December 2016, Reflective Log) } \\
\text { "For rich pictures activity, we had to agree on which pictures were most significant in terms of the idea we intended to present [...] team members made an } \\
\text { effort to be as creative as possible within the given timeframes [...] The workshop was a reminder of different project aspects for example communication, } \\
\text { leadership, time, resources and the effect these can have on a project in the real world." (13 December 2016, Reflective Log) }\end{array}$ \\
\hline
\end{tabular}

Table 1 (Continued). Example feedback from recent cohorts of students. 
Another point worth mentioning here is the uniqueness of this activity for the students mentioned in the majority of their reflective logs and course evaluations (refer to Table 1). The literature has so often expounded the need for consistency and coherence of approaches across an entire curriculum and that active participatory approaches should be encouraged as far as possible (see Quist et al., 2006, and; Segalàs et al., 2009).

It is perhaps due to the uniqueness of this activity, which took the students by surprise, that such a rapid turnaround from their zone of discomfort to achieving a zone of discovery and dialogue was enabled. Had such an approach been commonplace across the curriculum, students might end up in a zone of disenfranchisement with the activity and not see the point of engaging with the discussions (Mulder, 2010). It would have merely been more of the same!

\section{Artefacts and the role of aesthetic knowledge: maximizing sensible knowledge beyond text}

Physical objects (or artefacts) matter in getting students to engage meaningfully in generating the "Rich pictures" about their visions of what sustainable future means for them (Rehal and Birgersson, 2006). Whether this referred to the process of moving the tables and chairs to create an open space, or the visual images on the floor that compelled them to circulate around the room and organically form their groups, artefacts possess latent power in stimulating a response. The role that artefacts play in pedagogical practice is certainly under-explored (see e.g. Bernold, 2007 for an exception). Here, we experienced another striking observation. Despite claims of preferring textual and numerical information, students across every cohort tended to place more emphasis on the visual images than on the textual "wiki-terms". Perhaps the fact that the activity was named "Rich pictures" influenced the students' decisions as to what the outputs should look like, although at no point was there any mention of the need to use the visual images in their final posters. In fact, on numerous occasions throughout each workshop, we repeatedly indicated that the students did not have to use any of the visual aids provided - indeed a number of students enjoyed the visual images so much that many decided to take some home as a souvenir from the workshop. Some of the students even availed themselves of supplementary artefacts, e.g. plastic mugs and bits of garbage with which to enrich their posters, claiming they were doing their bit for the environment by recycling waste into something productively artistic.

Once the posters were produced, students then placed these on the walls around the room, transforming the space into an ad-hoc 'art gallery.' Students were asked to 'vote with their feet' and stand by the poster of their preference. This was done to achieve some order in the room; in reality, students were free to circulate around the room and continue with the dialogue whilst we circulated to discuss the posters with them (see Fig. 2 below for three examples of the "Rich pictures" produced). A striking event occurred in one of the UK workshops that is worth discussing here. In one of the posters, a particular image caused great controversy among the students, namely that of Thomas Beatie, a female-to-male transgendered person who made headlines in 2008 as the world's first pregnant man (see Fig. 3 Left below). A number of students had protested at the use of this particular image because it was deemed "unethical", "immoral", "counter to our religious beliefs", and "unnatural." A rather lengthy exchange of views lasting up to 20 minutes ensued, and another group of students joined in to see what the commotion was about. Eventually, a student singled out an image of human evolution and suggested that countless number of hours sitting in front of a computer was equally "unnatural." Without the intervention of the educators, the students had generated and engaged in a debate on the possibilities and problems of technological advances, the role of engineers in an ethical space, and the still taboo issues of gender and sexuality.

This, in our view, convincingly demonstrates the power artefacts have in unlocking what scholars term as "aesthetic knowledge," where knowledge is "symbolic, consisting of knowledge in the form of signs and symbols" and "experiential, consisting of feelings and embodied experiences that emerge through knowledge use" (Ewenstein and Whyte, 2007: 689). Indeed, knowledge remains 
incomplete if it does not capture the imagination of the senses (Strati, 2007; see also Gherardi et al., 2013). In this respect, we have observed how the artefacts - the sight of the images, the sound of the background music, and the conflicts that arose between hearts and minds during the discussions and formulation of the rich picture - all form part of the transformative learning experience necessary to inculcate an understanding of the complexities of sustainable development (Moore, 2005b). For Gherardi (2003),

"Learning thus becomes an epistemic relation with the world, and it takes place as much in people's minds as in the social relations among them, in the oral, written and "visual" texts which convey ideas and knowledge from one context to another [...] knowledge also comprises the ideas of knowing how to do, live, and listen." (p. 352; 354)

For such learning to take place, there is a need to verbalise, to externalise, so that ideas, perspectives and emotions may meet, and even clash. This verbalisation provides the invaluable opportunity to see and hear what we think, and consequently to question that thinking.

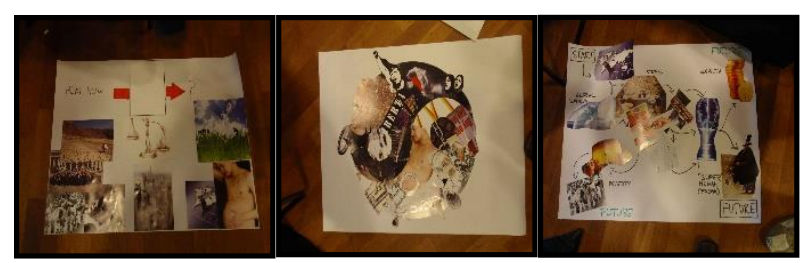

Figure 2: Examples of "Rich pictures" produced.

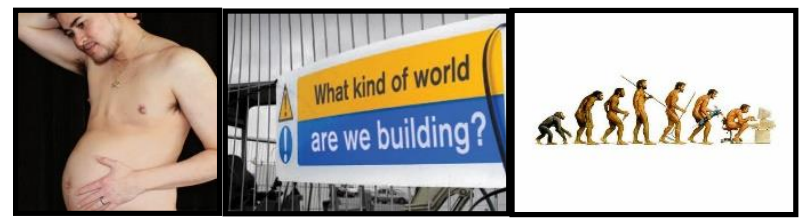

Figure 3: Examples of visual aids used (Left: a picture of a pregnant man; Middle: sign hung on a fence at a construction site, and Right: a picture depicting human evolution).

\section{Discussion and Conclusions}

A qualitative reflection of an "Open-space" workshop format in encouraging postgraduate engineering management students to appreciate the complexities of sustainable development has been presented in this article. This workshop is a novel example of responding to calls for transformative learning and collaboration in the teaching and learning of sustainable development (Moore, 2005a and 2005b; Jones, 2010, and; Mulder, 2010). We have deliberately steered clear from emphasising the role of the educator in order to elevate the status of the artefacts used during the workshop, in our efforts to explore the role these artefacts play in unleashing aesthetic knowledge to facilitate crossing of the threshold of understanding sustainable development.

While the educators played the role, to some extent, of silent witnesses, the educator's presence was not diminished in the workshops; it was merely different. The workshops would not have materialised without the organisational efforts of the educators in the first place. But this is also potentially problematic, since the choices of what images to include, what background music to play and how the workshop is loosely orchestrated remain within the firm grasp of the educator. Thus, do the students really own their transformative learning experience? Or are the students simply hapless participants, where the social construction of their knowledge is merely the fruits of an elaborate puppetry exercise designed by the educator? More research is needed to examine the power relations between the educator, the learners, and the artefacts used in the workshops described. There is also a need for more studies that go deeper into the educator's value systems, to examine how these intertwine with the content, processes, tools and artefacts used in the construction of knowledge. It is argued that our autoethnographic approach allowed us to lay bare our shared value system, which in turn shaped our teaching and learning practices, tools and artefacts adopted in the workshop (Moustakim, 2007, and; Hannon and Bretag, 2010).

Sustainable development is a troublesome concept to teach. We have shown how the workshops in 
general and the pictorial artefacts have stimulated students' interest in the subject, at least to engage in and with meaningful and sometimes controversial discussions, far more quickly and naturally than conventional text-based approaches to higher education. Our workshop also joins a growing line of innovative ways of thinking outside the disciplinary box in teaching and learning about sustainable development (PetersenBoring and Forbes, 2013). The mundane tools and artefacts also meant that we were able to deliver the workshop with a very modest budget for small and large cohorts of students alike. It is also worth noting that both the Swedish and British programmes attract quite a number of international students. Based on our observations, pictorial artefacts can offer an effective media for encouraging cross-cultural conversations among students from different backgrounds to articulate different sustainable futures, and challenge one another on their assumptions underpinning their respective vision of the future.

While we have so far been sanguine about the pictorial artefacts, it would be naive and even hubristic to suggest that the tools used in the workshop would offer a universal panacea for knowledge creation, however incomplete, of sustainable development to the students. It is inevitable that some students will have appropriated much more about sustainable development than others in the workshop. Recent evidence indicates that there are distinctions to be made between object/artistic, spatial/scientific and verbal/literary creativities (Kozhevinikov et al., 2013). From the student feedback, it is clear that some were more comfortable in relating to the pictorial artefacts than others. This difference in learning style can also be seen in the varied range of posters produced over the years. Therefore, more work needs to be done to develop a broader range of artefacts so that educators can cater to a wider range of creative styles.

What are the implications for engineering educators in the project management sphere? As

6 In 2017, we modified the workshop in Sweden to add the possibility for students to enact their poster in a twominute play. While it is too early to evaluate the effectiveness of this adaptation, our preliminary we argued, knowledge about sustainable development is incomplete and, as a wicked problem, there is no certainty of a correct answer (Hjorth and Bagheri, 2006). This means that it is unlikely that a codified body of disciplinary knowledge will be created in the immediate future, which lays down the laws of sustainable development. A more likely scenario is that teaching and learning of sustainable development will forever remain a precarious subject (Gherardi, 2003), where dialogue rather than transmission of disciplinary knowledge should be encouraged (Moustakim, 2007). In the engineering project organization field, researchers have long identified the need for messy talk (Dossick and Neff, 2011) and societal engagement (Hartmann and Dewulf, 2015). Yet, dialogue tends to be actively discouraged in our pedagogical practices, with educators and students opting for the more efficient, but perhaps less effective, didactic lecture as a means to prescribe knowledge (Bernold, 2007; see also Moustakim, 2007, and; Jones, 2010).

It is hoped that the "Open-space" workshop examined in this article provides an example for educators to rethink their teaching and learning practices that could foster a playful but productive setting (Meadows et al., 2016) for students to engage in dialogue about their sustainable future. We should also mention that we both benefit from a fair amount of freedom in our course design. This is not the case for all educators. We are also deeply committed to the notion of learning as a participative, ongoing activity in which both teachers and students continuously learn from each other. The teacher's job is to create environments, methods and tools for this to happen. We have learnt from our students and from each other over the years, and have continuously been adapting and improving the workshop ${ }^{6}$.

The qualitative analysis of the role of artefacts in constructing (aesthetic) knowledge about sustainable development is a significant point to conclude. Although engineering students claim to relate better to textual and numerical information,

observations suggest that the combination of art and drama awakened the students' senses into acting on their visions of their imagined sustainable futures. 
packaged within discrete, concretised and commoditised chunks of knowledge, our observations of the workshops described in this article suggest otherwise. We found students related more fruitfully and engaged more enthusiastically with visual images, which we viewed as a source for stimulating ideas and raising often uncomfortable questions about sustainable development and their role in it. Our contribution here is to open up our senses as educators to the appropriateness of the tools and artefacts, including the spatial arrangements of our teaching and learning activities. There is room for more research into how the many, often messy combinations of textual information, images, background music and dialogues that develop among students and between students and educators can go some way to encourage sensory engagement among the students (Gherardi, 2003). For us, the workshop along with the tools provide a more holistic way of creating knowledge, especially in such a topic that contains so much that is unknown as sustainable development.

To summarise, there are a number of areas that would benefit from further inquiry, including the need to investigate the role of the educator in pursuing such a pedagogical approach, the negotiation of power relations between educators and learners in such contexts, and the possibility of formalising such practices for greater, wider adoption in educating students in engineering project organisation to imagine a sustainable future.

\section{References}

Allenby, B., Allen, D. and Davidson, C. (2007) Sustainable engineering: from myth to mechanism. Environmental Quality Management, 17(1): 17-26.

Argyris, C. and Schön, D. A. (1974) Theory in Practice: Increasing professional effectiveness. San Francisco: Jossey-Bass.

Azapagic, A., Perdan, S. and Shallcross, D. (2005) How much do engineering students know about sustainable development? The findings of an international survey and possible implications for the engineering curriculum. European Journal of Engineering Education, 30(1): 1-19.
Bergeå, O., Karlsson, R., Hedlund-Åström, A., Jacobsson, P. and Luttropp, C. (2006) Education for sustainability as a transformative learning process: a pedagogical experiment in EcoDesign doctoral education. Journal of Cleaner Production, 14(1516): 1431-1442.

Bernold, L. E. (2007) Teaching evaluations for construction engineering and management: opportunity to move us forward. Journal of Construction Engineering and Management, 133(2): 146-156.

Boyle, C. (2004) Considerations on educating engineers in sustainability. International Journal of Sustainability in Higher Education, 5(2): 147-155.

Bubou, G. M., Offor, I. T. and Bappa, A. S. (2017) Why research-informed teaching in engineering education? A review of the evidence. European Journal of Engineering Education, 42(3), 323-335.

Chan, P. and Cooper, R. (2010) Constructing Futures: Industry leaders and futures thinking in construction. Oxford: Wiley-Blackwell.

Chau, K. W. (2007) Incorporation of sustainability concepts into a civil engineering curriculum. Journal of Professional Issues in Engineering Education and Practice, 133(3): 188-191.

Colucci-Gray, L., Camino, E., Barbiero, G., and Gray, D. (2006) From scientific literacy to sustainability literacy: an ecological framework for education. Science Education, 90(2): 227-252.

de Haan, G. (2006) 'The BLK '21' programme in Germany: a 'Gestaltungskompetenz'-based model for education for sustainable development. Environmental Education Research, 12(1): 19-32.

Dossick, C. S. and Neff, G. (2011) Messy talk and clean technology: Communication, problem-solving and collaboration using Building Information Modelling. Engineering Project Organization Journal, 1(2): 8393.

Duah, F., Croft, T. and Inglis, M. (2014) Can peer assisted learning be effective in undergraduate mathematics? International Journal of Mathematical Education in Science and Technology, 45(4): 552565.

Ekins, P. (2003) Identifying critical natural capital: conclusions about critical natural capital. Ecological Economics, 44(2-3): 277-292.

Elkington, K. (2004) Enter the triple bottom line. In: A. Henriques and J. Richardson (Eds.) The Triple Bottom Line: Does it all add up? Assessing the Sustainability of Business and CSR. London: Earthscan. pp. 1-17.

Ewenstein, B. and Whyte, J. (2007) Beyond words: aesthetic knowledge and knowing in organizations. Organization Studies, 28(5): 689-708. 
Fenner, R. A., Ainger, C. M., Cruickshank, H. J. and Guthrie, P. M. (2005) Embedding sustainable development at Cambridge University Engineering Department. International Journal of Sustainability in Higher Education, 6(3): 229-241.

Forrest, K. A., Judd, K. R. and Davison, J. R. (2012) Coming to know within 'healthy uncertainty': An autoethnography of engagement and transformation in undergraduate education. Teaching in Higher Education, 17(6): 710-721.

Gherardi, S. (2003) Knowing as desiring: mythic knowledge and the knowledge journey in communities of practitioners. Journal of Workplace Learning, 15(7/8): 352-358.

Gherardi, S., Meriläinen, S., Strati, A. and Valtonen, A. (2013) Editorial: A practice-based view on the body, senses and knowing in organization. Scandinavian Journal of Management, 29(4): 333-337.

Hains-Wesson, R. and Young, K. (2017) A collaborative autoethnography study to inform the teaching of reflective practice in STEM. Higher Education Research and Development, 36(2): 297-310.

Hannon, J. and Bretag (2010) Negotiating contested discourses of learning technologies in higher education. Journal of Educational Technology and Society, 13(1): 106-120.

Hartmann, A. and Dewulf, G. (2015) Community engagement in project organization research: The contextualization of the research process. Engineering Project Organization Journal, 5(2-3): 77-94.

Hjorth, P. and Bagheri, A. (2006) Navigating towards sustainable development: A system dynamics approach. Futures, 38(1): 74-92.

Holmberg, J. (2014) Transformative learning and leadership for a sustainable future: Challenge Lab at Chalmers University of Technology. In: P. Corcoran, B. Hollingshead, H. Lotz-Sisitka, A. Wals, and J. Weakland (Eds.) Intergenerational Learning and Transformative Leadership for Sustainable Futures. Wagenigen: Wagenigen Academic Publishers. pp. 91-102.

Hussey, T. and Smith, P. (2002) The trouble with learning outcomes. Active Learning in Higher Education, 3(3): 220-233.

Jones, S. E. (2010) Reflections on the lecture: outmoded medium or instrument of inspiration? Journal of Further and Higher Education, 31(4): 397-406.

Kozhevnikov, M., Kozhevnikov, M., Yu, C. J. and Blazhenkova, O. (2013) Creativity, visualization abilities, and visual cognitive style. British Journal of Educational Psychology, 83(2): 196-209.

Lönngren, J. and Svanström, M. (2016) Systems thinking for dealing with wicked sustainability problems: Beyond functionalist approaches. In: W.
L. Filho and S. Nesbit (Eds.) New Developments in Engineering Education for Sustainable Development. Cham, Switzerland: Springer. pp. 151160.

Lönngren, J. , Svanström, M., Ingerman, A. And Holmberg, J. (2016) Dealing with the multidimensionality of sustainability through the use of multiple perspectives - a theoretical framework. European Journal of Engineering Education, 41(3): 342-352.

Martins, A. A., Mata, T. M. and Costa, C. A. V. (2006) Education for sustainability: challenges and trends. Clean Technologies and Environmental Policy, 8(1): 31-37.

Meadows, D., Sweeney, L. B. and Mehers, G. M. (2016) The Climate Change Playbook: 22 Systems thinking games for more effective communication about climate change. White River Junction, Vermont: Chelsea Green Publishing.

Moore, J. (2005a) Seven recommendations for creating sustainability education at the university level: a guide for change agents. International Journal of Sustainability in Higher Education, 6(4): 326-339.

Moore, J. (2005b) Is higher education ready for transformative learning? A question explored in the study of sustainability. Journal of Transformative Education, 3(1): 76-91.

Moustakim, M. (2007) From transmission to dialogue: Promoting critical engagement in higher education teaching and learning. Educational Action Research, 15(2): 209-220.

Mulder, K. F. (2010) Don't preach. Practice! Value laden statements in academic sustainability education. International Journal of Sustainability in Higher Education, 11(1): 74-85.

Neumayer, E. (1999) Global warming: discounting is not the issue, but substitutability is. Energy Policy, 27(1): 33-43.

Owen, H. (2008) Open Space Technology: A user's guide. 3 Ed. San Francisco: Berrett-Koehler.

Pearce, D. W., Markandya, A. and Barbier, E. (1989) Blueprint for a Green Economy. London: Earthscan.

Petersen-Boring, W. and Forbes, W. (Eds.) (2013) Teaching Sustainability: Perspectives from the humanities and social sciences. Nacogdoches, Texas: Stephen F. Austin University Press.

Pillay, D., Naicker, I. and Pithouse-Morgan (Eds.) (2016) Academic Autoethnographies: Inside teaching in higher education. Rotterdam, the Netherlands: Sense Publishers.

Quist, J., Rammelt, C., Overschie, M. and de Werk G. (2006) Backcasting for sustainability in engineering education: the case of Delft University of Technology. Journal of Cleaner Production, 14(911): 868-876. 
Räisänen, C. (2004) Multiple literacies for the "new" engineer: learning to learn In Integrating Content and Language: Meeting the challenge of a multilingual higher education, ICL Proceedings. Maastrict: Maastrict University.

Rehal, S. and Birgersson, L. (2006) Associative images as a communication tool to improve the dialogue between designers and end-users. In: Proceedings: Ninth international symposium of the International Social Security Association (ISSA) entitled "Design process and human factors integration: optimizing company performance", Nice, 1 - 3 March.

Rittel, H. W. J. and Webber, M. M. (1973) Dilemmas in a General Theory of Planning. Policy Sciences, 4(2): 155-169.

Sammalisto, K. and Lindhqvist, T. (2008) Integration of sustainability in higher education: a study with international perspectives. Innovative Higher Education, 32(4): 221-233.

Schön, D. (1984) The Reflective Practitioner. New York: The Perseus Book Group.

Segalàs, J., Ferrer-Balas, D. and Mulder, K. F. (2009) What do engineering students learn in sustainability courses? The effect of the pedagogical approach. Journal of Cleaner Production, 18(3): 275-284.

Stephens, J. C., Hernandez, M. E., Román, M., Graham, A. C. and Scholz, R. W. (2008) Higher education as a change agent for sustainability in different cultures and contexts. International Journal of Sustainability in Higher Education, 9(3): 317-338.

Strati, A. (2007) Sensible knowledge and practice-based learning. Management Learning, 38(1): 61-77.

Taylor, S. S. (2000) Aesthetic knowledge in academia: capitalist pigs at the Academy of Management. Journal of Management Inquiry, 9(3): 304-328.

UK Government (1999) A Better Quality of Life: A strategy for sustainable development for the $U K$. London: HMSO.

UN (2005) World Summit Outcome: Resolution adopted by the General Assembly on 16 September 2005. A/RES/60/1. Accessed through https://documents-ddsny.un.org/doc/UNDOC/GEN/N05/487/60/PDF/ N0548760.pdf?OpenElement on 2 July 2017.

Wacknernagel, M., Monfreda, C., Schulz, N. B., Erb, K., Haberl, H. and Krausmann, F. (2004) Calculating national and global ecological footprint time series: resolving conceptual challenges. Land Use Policy, 21(3): 271-278.

World Commission on Environment and Development (1987) Our Common Future: World commission on environment and development. Oxford: Oxford University Press.

Wright, T. (2010) University presidents' conceptualizations of sustainability in higher education. International Journal of Sustainability in Higher Education, 11(1): 61-73. 